\title{
A simple cost-effective PSR LED driver without auxiliary winding
}

\author{
Weidong Nie ${ }^{1 \mathrm{a})}$, Jin $\mathbf{W u}^{2 \mathrm{~b})}$, and Zongguang $\mathbf{Y u}^{1}$ \\ ${ }^{1}$ School of Digital Media, Jiangnan University, Wuxi, China \\ ${ }^{2}$ Wuxi Branch, Southeast University, Wuxi, China \\ a)youdanwd@163.com \\ b) Corresponding author, jwu@seu.deu.cn
}

Abstract: A simple cost-effective LED driver based on the primaryside-regulation (PSR) scheme without auxiliary winding is proposed and designed. The driver operates in discontinuous conduction mode (DCM). By means of controlling the discharging and charging of an internal timing capacitor, the conduction time $\mathrm{T}_{\mathrm{on} \_\mathrm{s}}$ of the secondaryside current is monitored and the ratio of $T_{\mathrm{on}_{-} \mathrm{s}}$ to the switching period $\mathrm{T}_{\mathrm{s}}$ is kept constant, resulting in a constant output current. The output current zero cross detecting (ZCD) signal is sensed by the negative change of power MOSFET's source voltage due to the resonance of the primary winding with the parasitic capacitor $\mathrm{C}_{\mathrm{dss}}$ of MOSFET. The driving IC and $650 \mathrm{~V}$ power MOSFET chips are packaged together in SOP-8. The proposed driver is implemented with few external components and its size is minimized. Experimental results show that the current variation is within $\pm 3 \%$, and the efficiency exceeds $80 \%$ at the output power of $3-5 \mathrm{~W}$ under universal input voltage.

Keywords: LED driver, primary-side-regulation, cost-effective, without auxiliary winding

Classification: Integrated circuits

\section{References}

[1] X. Chen, T. Jiang, S. Zhao, H. Zeng and J. Zhang: IEEE Applied Power Electron. Conf. and Expo. (2013) 1859.

[2] C.-L. Yeh, T.-W. Hou and C.-M. Chao: IEICE Electron. Express 6 [24] (2009) 1757.

[3] H.-H. Chou, Y.-S. Hwang and J.-J. Chen: IEEE Trans. Power Electron. 28 [10] (2013) 4811.

[4] A. Shteynberg, J. Zheng, H. Rodriguez, M. Telefus and D. Zhou: U.S. Patent 6972969 (2005).

[5] Texas Instruments: TPS92315EVM User's Guide, http://www.ti.com/lit/ ug/slvu825a/slvu825a.pdf

[6] STMicroelectronics: 3.2 W LED power supply based HVLED805 (2011) http://www.stmicroelectronics.com.cn/st-web-ui/static/active/en/ resource/technical/document/application_note/DM00024649.pdf 


\section{Introduction}

White light emitting diode (LED) has attracted a lot of attention from both industry and resident for its high efficiency, ease to drive, environmental friendliness, and long lifespan. The LED lamps are being used to replace the incandescent bulbs and fluorescent lamps $[1,2,3]$.

The isolated AC-to-DC converters have been widely used among the LED driving circuits due to the safety and simplicity. In order to regulate the output current of the driving circuits precisely, the primary-sideregulation (PSR) and the secondary-side-regulation (SSR) scheme are usually adopted. PSR technique increasingly draws people's attention because its elimination of opto-coupler, which results in lower cost and simpler control circuit. Moreover, the life and temperature issues related to the opto-coupler are also eliminated $[2,3]$.

The conventional solution for PSR scheme is often to adopt an additional auxiliary winding for sensing the output current. At the time that the secondary winding current reaches zero, the zero cross detecting (ZCD) signal can be sensed by the auxiliary winding. In order to avoid the backflow of auxiliary winding current, the rectifier diode is often required $[3,4,5,6]$.

The efficiency, lifetime and robustness are important for LED drivers. Besides, the low cost, compact volume, and simplicity are the key factors in low power applications. For these reasons, we attempt to develop a simple cost-effective PSR LED driver. In contrast to the conventional PSR LED driver, it does not need an auxiliary winding for sensing the ZCD signal of output current, but it still maintains a good LED current accuracy and a high efficiency under universal input voltage. When the secondary-side current reaches zero, the ZCD signal is sensed by the negative change of the power MOSFET's source voltage, due to the resonance of the primary winding with the parasitic drain-to-source capacitance $\mathrm{C}_{\mathrm{dss}}$ of MOSFET. We combine the $650 \mathrm{~V}$ power MOSFET switch chip with controlling IC chip in SOP-8 to make the converter small. An LED lighting board is implemented with minimized external component count and size. At LEDload power of $3-5 \mathrm{~W}$, its current variation is within $\pm 3 \%$ and its power conversion efficiency exceeds $80 \%$ under universal input voltage.

\section{Design and operation principle}

Based on a flyback converter, the converter is composed of bridge rectifier, bulk capacitor $\mathrm{C}_{\mathrm{b}}$, transformer $\mathrm{T}$, bypass capacitor $\mathrm{C}_{\mathrm{Vcc}}$, startup resistor $\mathrm{R}_{\mathrm{st}}$, snubber circuit, LED driving IC (including built-in power MOSFET), current sense resistor $R_{c s}$, output rectifier diode $D_{o}$ and capacitor $C_{o}$. The LED driving IC consists of control parts and protection parts. The latter parts include LEDs open/short circuit protection, over-temperature protection etc. The control parts of the driving IC include the charging current circuit $\mathrm{I}_{1}$ and discharging current circuit $\mathrm{I}_{2}$, the main switch control circuit and ZCD signal sense circuit. Fig. 1 shows the block diagram of the circuit implementation along with driving IC.

The proposed LED driver uses a cascade configuration for the power switch. The gate of power MOSFET is held at a DC voltage $\mathrm{V}_{\mathrm{cc}}(14 \mathrm{~V})$, which is obtained by a linear shunt regulator. It employs an internal 


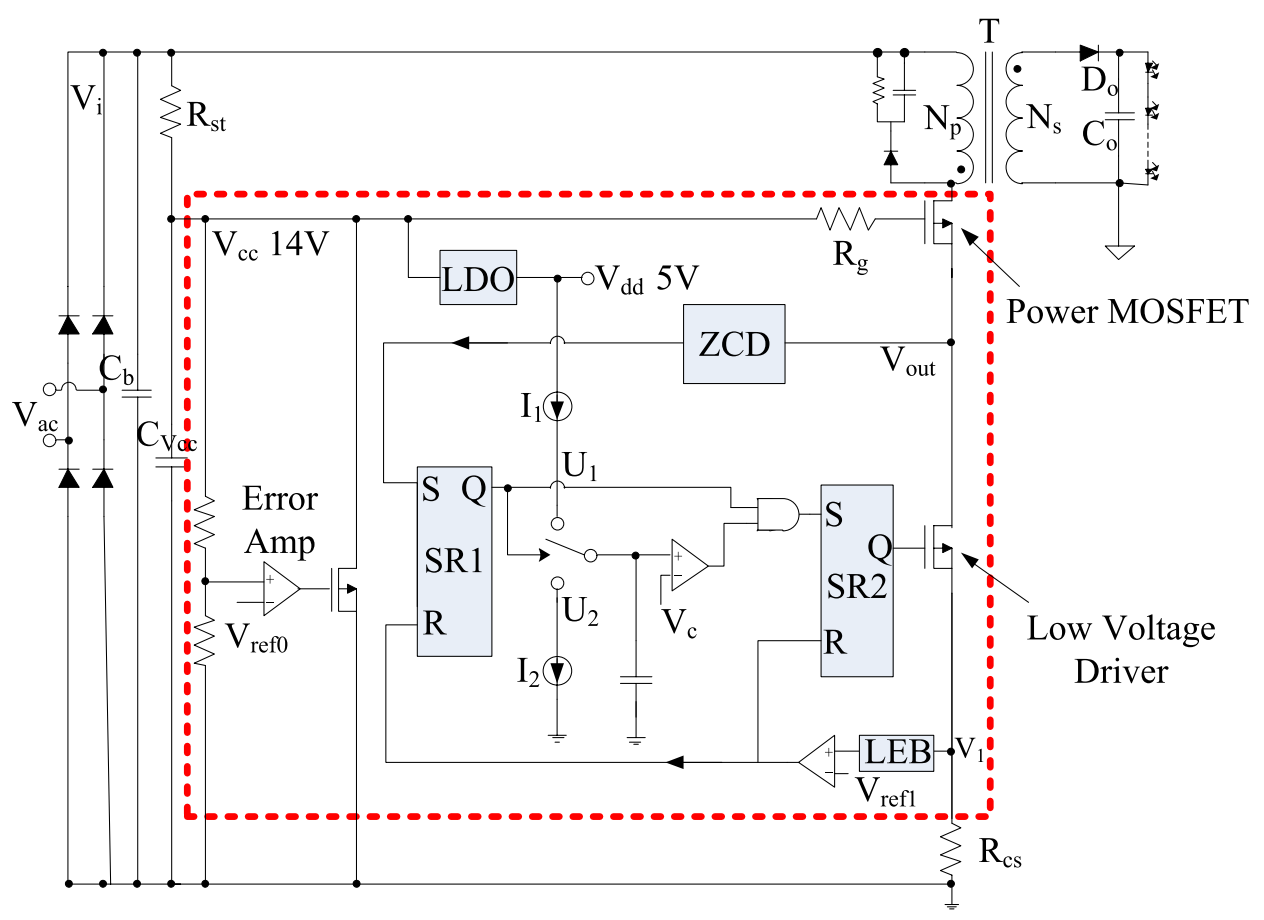

Fig. 1. Block diagram of the circuit implementation along with driving IC

bandgap reference $\mathrm{V}_{\text {ref0 }}(2.5 \mathrm{~V})$, an error amplifier, a shunt NMOS and the external resistor $R_{\mathrm{st}} . \mathrm{V}_{\mathrm{cc}}$ is also used to drive low voltage driver and the power MOSFET. A DC voltage $\mathrm{V}_{\mathrm{dd}}(5 \mathrm{~V})$ provided by a low dropout voltage regulator is adopted to power other parts.

Fig. 2 shows the timing diagram of relevant signals for the proposed scheme.
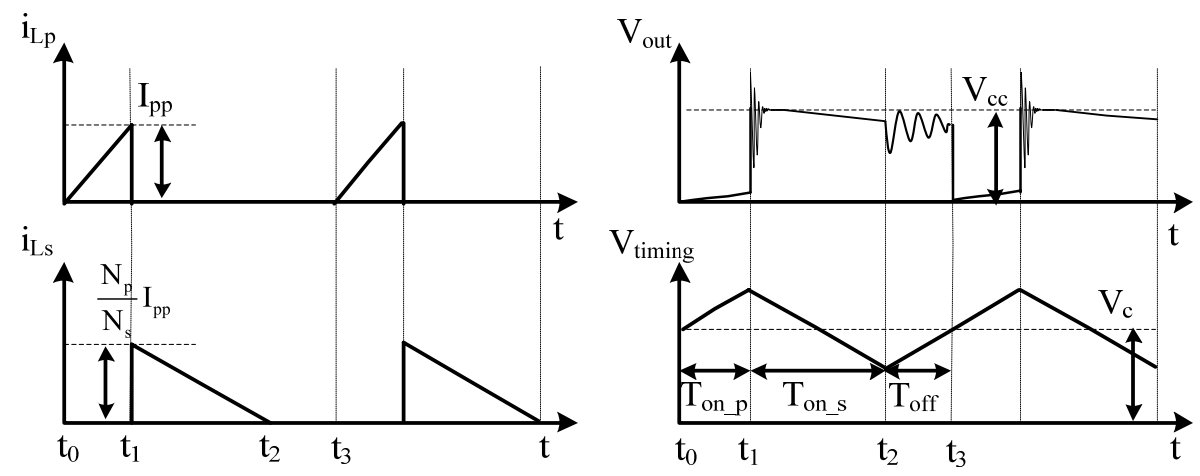

Fig. 2. The timing diagram of relevant signals

1) Interval $1: t_{0} \sim t_{1}$

In this time interval, the power switch is turned on. The primary current $i_{L p}$ increases linearly (Fig. 2) and the converter stores its energy in its transformer. At the moment when the power transistor begins to turn on, the voltage across the timing capacitor $V_{\text {timing }}$ is at a fixed voltage $V_{c}$. During interval 1, the analog switch $\mathrm{U}_{1}$ is turned on and $\mathrm{U}_{2}$ is turned off. The current $I_{1}$ charges the timing capacitor, resulting in the increase of capacitor voltage $\mathrm{V}_{\text {timing }}$ (Fig. 2). With the increase of primary current, the voltage $V_{1}$ across current sense resistor $R_{\mathrm{cs}}$ develops.

2) Interval 2: $t_{1} \sim t_{2}$

Once $V_{1}$ reaches the setting point $V_{\text {ref } 1}$, interval 2 begins. As the output of 
comparator changes from low to high level, the flip-flop SR1 will be reset to "0" and the flip-flop SR2 will be triggered to turn off the power transistor. The converter releases its stored energy to its secondary winding, and the magnetizing current $\mathrm{i}_{\mathrm{Ls}}$ decreases linearly (Fig. 2). Meanwhile, the analog switch $\mathrm{U}_{1}$ is turned off and $\mathrm{U}_{2}$ is turned on. The timing capacitor begins to discharge by the current $\mathrm{I}_{2}$, resulting in the decrease of the timing capacitor voltage $\mathrm{V}_{\text {timing }}$ (Fig. 2).

3) Interval 3: $t_{2} \sim t_{3}$

As the secondary winding has run up energy, the MOSFET's drain and source voltages begin to resonate. Once the source voltage $V_{\text {out }}$ of the MOSFET decreases to a certain value, the ZCD sense circuit will generate a logic high output, and the reasons will be described in detail in the next section. Thus the flip-flop SR1 will be changed from "0" to "1". At same time, the analog switch $\mathrm{U}_{1}$ becomes $\mathrm{ON}$ and $\mathrm{U}_{2}$ becomes $\mathrm{OFF}$. Then the timing capacitor is charged by the current $\mathrm{I}_{1}$. After the voltage of timing capacitor turns bigger than $\mathrm{V}_{\mathrm{c}}$, the power MOSFET turns on, indicating that interval 1 begins again.

The converter operates in discontinuous conduction mode (DCM), and:

$$
\begin{gathered}
I_{L E D}=I_{s} \frac{T_{o n_{-} s}}{T_{s}}=\frac{I_{s p} T_{o n \_s}}{2 T_{s}} \\
I_{s p}=\frac{N_{p}}{N_{s}} I_{p p} \\
V_{L E D}=L_{s} \frac{I_{s p}}{T_{o n \_s}}=L_{p}\left(\frac{N_{s}}{N_{p}}\right)^{2} \frac{I_{s p}}{T_{o n \_s}}
\end{gathered}
$$

Where $\mathrm{N}_{\mathrm{p}}$ and $\mathrm{L}_{\mathrm{p}}$ are the primary turns and magnetizing inductance, while $\mathrm{N}_{\mathrm{s}}$ and $\mathrm{L}_{\mathrm{s}}$ are the secondary turns and magnetizing inductance of the transformer, respectively. $I_{\mathrm{S}}$ is the average current on the secondary-side during $\mathrm{T}_{\text {on_s }}$. $\mathrm{I}_{\mathrm{LED}}$ and $\mathrm{V}_{\text {LED }}$ are the output current and voltage, respectively. $T_{\text {on_s }_{\mathrm{s}}}$ is the secondary-side discharge time, $\mathrm{T}_{\mathrm{s}}$ is the switching period time. $\mathrm{I}_{\mathrm{pp}}$ and $\mathrm{I}_{\mathrm{sp}}$ are the peak currents on the transformer primaryside and the secondary-side respectively.

Because $I_{1}$ is designed to be equal to $I_{2}, T_{\text {on_s }}$ is equal to the sum of $T_{\text {on_p }}$ and $T_{\text {off. }} T_{\text {on_p }}$ is the time that the power MOSFET is ON, $T_{\text {off }}$ is the dead time neither primary-side MOSFET nor secondary-side diode is ON.

$$
T_{s}=T_{o n \_s}+T_{o n \_p}+T_{o f f}=2 T_{o n \_s}
$$

Combining (1), (2) and (4), the output current $\mathrm{I}_{\mathrm{LED}}$ can be expressed as

$$
I_{L E D}=\frac{I_{p p} N_{p}}{4 N_{s}}
$$

The peak current $I_{p p}$ is determined by the external current sense resistor $R_{\text {cs }}$ and internal $V_{\text {ref1 }}$. As the peak $I_{p p}$ and turns ratio $N_{p} / N_{s}$ are fixed, the output current $\mathrm{I}_{\mathrm{LED}}$ will keep constant. From (1), (3) and (4), the frequency $\mathrm{f}$ can be obtained.

$$
f=\frac{1}{T_{s}}=\frac{1}{2 T_{\text {on_s }}}=\frac{1}{8}\left(\frac{N_{p}}{N_{s}}\right)^{2} \frac{V_{L E D}}{L_{p} I_{L E D}}
$$


According to (6), the frequency $\mathrm{f}$ is developed with the increase of the $\mathrm{V}_{\text {LED }}$. When the input voltage $\mathrm{V}_{\text {in }}$ increases, the frequency will keep unchanged. This is because that the power MOSFET ON time $T_{\text {on_p }}$ will decrease, but the dead time $\mathrm{T}_{\text {off }}$ will increase, and their sum will keep constant according to (4).

For the lowest input voltage, the MOSFET ON time $T_{\text {on_p }}$ is the longest. And the voltage across the timing capacitor $\mathrm{V}_{\text {timing }}$ experiences the maximum value. When the operation condition is with maximum input voltage and minimum load, the dead time $\mathrm{T}_{\text {off }}$ is maximized. The voltage $\mathrm{V}_{\text {timing }}$ experiences the minimum value. So the reference voltage $\mathrm{V}_{\mathrm{c}}$ is set at $2.4 \mathrm{~V}$ to limit the voltage of $\mathrm{V}_{\text {timing }}$ located between $0 \mathrm{~V}$ and $\mathrm{V}_{\mathrm{dd}}(5 \mathrm{~V})$.

\section{ZCD sense circuit, operation principle and design con- sideration}

As shown in Fig. 3 (a), ZCD sense circuit consists of a resonant and a blanking circuit. The comparator in the blanking block senses the source voltage $V_{\text {out }}$ of power VDMOS across a resistor divider network $R_{3}$ and $R_{4}$ with a reference voltage $V_{\text {ref2 }}$. $V_{\text {ref2 }}$ is the divider voltage of $V_{\text {cc }}$ and equals to $\mathrm{V}_{\mathrm{cc}} * \mathrm{R}_{2} /\left(\mathrm{R}_{1}+\mathrm{R}_{2}\right) . \mathrm{V}_{\mathrm{ZCD}}$ is the divider voltage of $\mathrm{V}_{\text {out }}$ and equals to $\mathrm{V}_{\text {out }} * \mathrm{R}_{4} /$ $\left(\mathrm{R}_{3}+\mathrm{R}_{4}\right)$. In order to get the proper $\mathrm{DC}$ voltage of $\mathrm{V}_{\text {out }}$ before resonance, switches $\mathrm{K}_{1}$ and $\mathrm{K}_{2}$ are adopted.

In the interval $1\left(t_{0} \sim t_{1}\right), K_{1}$ and $K_{2}$ are OFF.

At $t=t_{1}$, the low voltage driver is turned off. Due to the leakage inductance of the primary winding and the parasitic capacitance, the ringing occurs. The ringing may be large enough to be misunderstood as a ZCD signal. To avoid unintended zero crossing detection, a blanking pulse is applied to the NOT gate to prevent the AND gate from turning to HIGH during blanking period. The fixed blanking time $\mathrm{T}_{\text {blank }}$ is set to be about $2 \mu \mathrm{s}$. At same time, $\mathrm{K}_{1}$ and $\mathrm{K}_{2}$ are turned on.

At $t=t_{1}$, the voltage across the parasitic gate-to-source capacitor $\mathrm{C}_{\mathrm{gss}}$ of power MOSFET is around $\mathrm{V}_{\mathrm{cc}}$. The carriers in the $\mathrm{C}_{\mathrm{gss}}$ are discharged through $\mathrm{R}_{\mathrm{g}}$ and $\mathrm{R}_{6}$, as shown in Fig. 3 (b). Since $\left(\mathrm{R}_{\mathrm{g}}+\mathrm{R}_{6}\right){ }^{*} \mathrm{C}_{\mathrm{gss}}$ « $\mathrm{T}_{\text {blank }}$ $(2 \mu \mathrm{s})$, the voltage across $\mathrm{C}_{\mathrm{gss}}$ decreases from $\mathrm{V}_{\mathrm{cc}}(14 \mathrm{~V})$ to $0 \mathrm{~V}$ and $\mathrm{V}_{\text {out }}$ develops from $0 \mathrm{~V}$ to $\mathrm{V}_{\mathrm{cc}}(14 \mathrm{~V})$ during blanking period.

After the blanking time $\mathrm{T}_{\text {blank }}, \mathrm{K}_{1}$ is $\mathrm{ON}$ and $\mathrm{K}_{2}$ is OFF. $\mathrm{C}_{\mathrm{gss}}$ is charged by $V_{\text {cc }}$ through $R_{g}, R_{3}$ and $R_{4}$, as shown in Fig. 3 (c). $V_{\text {out }}$ decreases gradually and experiences a voltage change $\Delta \mathrm{V}_{\text {on_s, }}$, which is given by

$$
\Delta V_{o_{-} \_}=\frac{R_{5}+R_{6}}{R_{3}+R_{4}+R_{5}+R_{6}} V_{c c}\left(1-e^{-t / \tau}\right)
$$

Where the time constant $\tau=\left[\mathrm{R}_{\mathrm{g}}+\left(\mathrm{R}_{5}+\mathrm{R}_{6}\right) / /\left(\mathrm{R}_{3}+\mathrm{R}_{4}\right)\right]^{*} \mathrm{C}_{\mathrm{gss}}$, and $\mathrm{t}=$ $\mathrm{T}_{\text {on_s }}-\mathrm{T}_{\text {blank }}$.

At $\mathrm{t}=\mathrm{t}_{2}, \mathrm{~V}_{\text {out }}=\mathrm{V}_{\mathrm{cc}}-\Delta \mathrm{V}_{\text {on_s }}$. At this time, the divider voltage $\mathrm{V}_{\mathrm{ZCD}}$ must be higher than $V_{\text {ref2 }}$. Otherwise the ZCD sense circuit will output a "1" signal to indicate a ZCD signal, although there is no ZCD signal in fact.

In the interval $3\left(t_{2} \sim t_{3}\right)$, the inductance of the primary winding and the parasitic capacitors begin to resonate. The parasitic capacitor $\mathrm{C}_{\mathrm{dss}}$ of the power MOSFET is put in use. The equivalent resonant circuit is shown in Fig. $3(d)$. As the values of $R_{5}$ and $R_{6}$ are big enough, the resonant circuit can be simplified, which is shown in Fig. 3 (e). It is a RLC circuit 


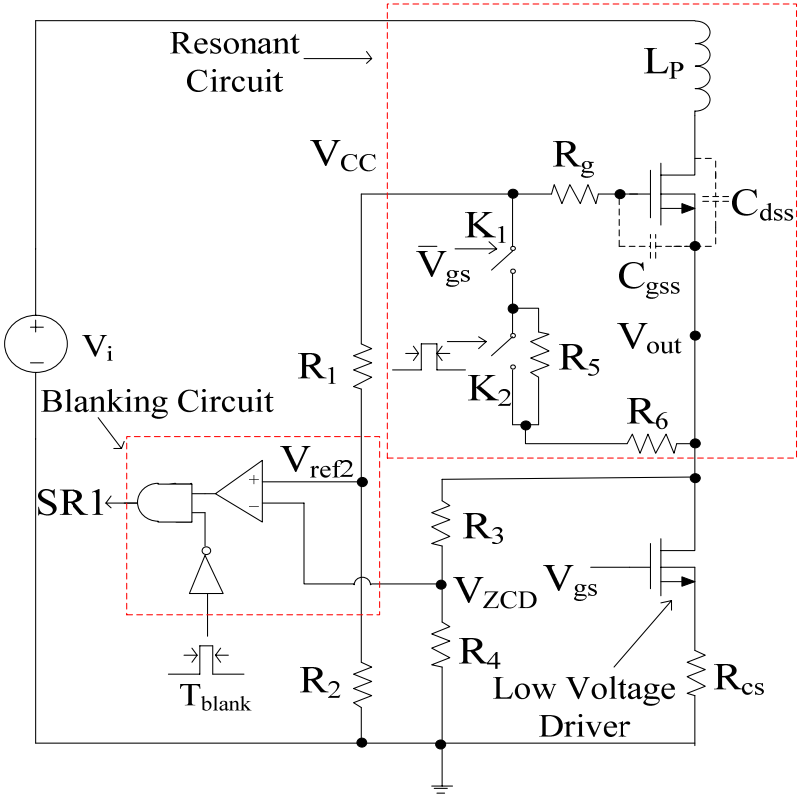

(a)

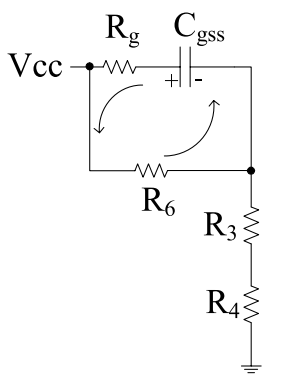

(b)

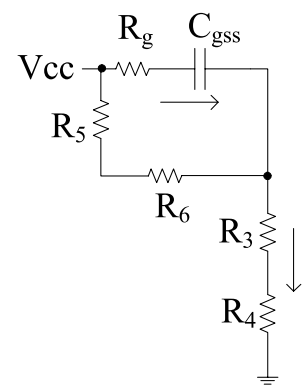

(c)

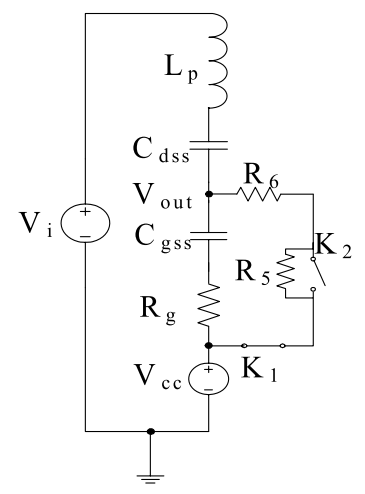

(d)

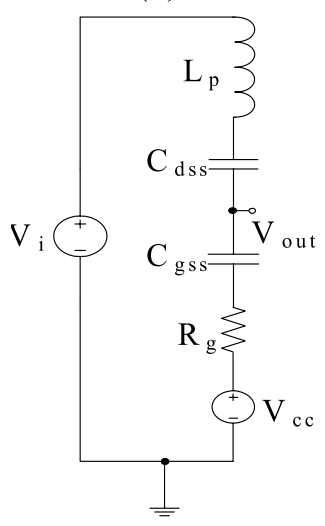

(e)

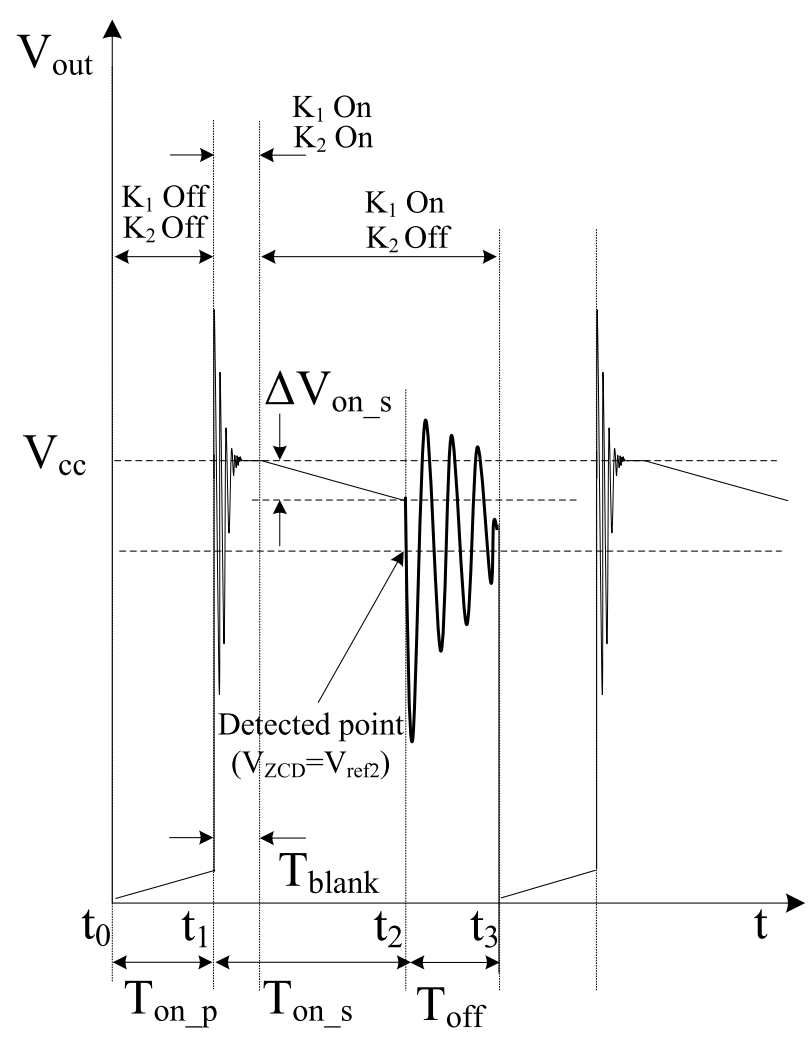

(f)

Fig. 3. (a) ZCD sense circuit, (b) Discharging circuit of $\mathrm{C}_{\mathrm{gss}}$ during blanking period, (c) Charging circuit of $\mathrm{C}_{\mathrm{gss}}$ during the remaining time $\left(\mathrm{T}_{\text {on_s }}-\mathrm{T}_{\text {blank }}\right)$ of interval 2 after blanking period, (d) Equivalent resonant circuit, (e) Simplified equivalent resonant circuit, (f) Waveform of $\mathrm{V}_{\text {out }}$ in different intervals 
which is made up of $\mathrm{L}_{\mathrm{p}}, \mathrm{C}_{\mathrm{d}}$ and $\mathrm{R}_{\mathrm{g}}$. $\mathrm{C}_{\mathrm{d}}$ is the total capacitance at the power MOSFET drain node. As $\mathrm{C}_{\mathrm{dss}}$ and $\mathrm{C}_{\mathrm{gss}}$ are in a series connection, and $\mathrm{C}_{\mathrm{gss}}$ » $\mathrm{C}_{\mathrm{dss}}$, resulting in $\mathrm{C}_{\mathrm{d}} \approx \mathrm{C}_{\mathrm{dss}}$.

At the beginning of resonant period $\left(t=t_{2}\right)$, the drain voltage of power MOSFET is $\left(\mathrm{V}_{\text {in }}+\left(\mathrm{N}_{\mathrm{p}} / \mathrm{N}_{\mathrm{s}}\right) * \mathrm{~V}_{\mathrm{LED}}\right)$. Here $\mathrm{V}_{\text {in }}$ is the rectified input voltage. A damped oscillation voltage at drain node of power MOSFET can be expressed as

$$
\Delta V_{D(t)}=\frac{N_{p}}{N_{s}} V_{L E D} e^{-\alpha t} \cos \left(2 \pi f_{r} t\right)
$$

Where $\alpha=\frac{R_{g}}{2 L_{p}}, f_{r}=\frac{1}{2 \pi \sqrt{L_{p} C_{d}}}$.

During resonant period, $\mathrm{R}_{\mathrm{g}}$ can be ignored because of its smaller value compared with the impedance of $\mathrm{C}_{\mathrm{gss}}$ and $\mathrm{C}_{\mathrm{dss}}$. So the source voltage $\mathrm{V}_{\text {out }}$ experiences a voltage change $\Delta \mathrm{V}_{\text {off }(\mathrm{t})}$ during resonant period which can be simply given by

$$
\Delta V_{o f f(t)}=\frac{C_{d s s}}{C_{d s s}+C_{\mathrm{g} s s}} \Delta V_{D(t)} \approx \frac{C_{d s s} N_{p}}{C_{\mathrm{g} s s} N_{s}} V_{L E D} e^{-\alpha t} \cos \left(2 \pi f_{r} t\right)
$$

In the negative half-cycle of the damped oscillation, $\mathrm{V}_{\text {out }}$ can be expressed as

$$
V_{\text {out }}=V_{\text {cc }}-\Delta V_{\text {on_s }}-\Delta V_{\text {off }(t)}
$$

Where $\left|\Delta V_{\text {off }(\mathrm{t})}\right|$ is the absolute value of $\Delta \mathrm{V}_{\text {off }(\mathrm{t})}$.

$\mathrm{V}_{\text {out }}$ decreases to its negative peak, resulting in the decrease of divider voltage $\mathrm{V}_{\mathrm{ZCD}}$. As indicated in Fig 3. (a), when $\mathrm{V}_{\mathrm{ZCD}}$ is equal to $\mathrm{V}_{\text {ref2 }}$, ZCD sense circuit will output a "1" signal to SET SR1, indicating that the ZCD signal is sensed.

When $\cos \left(2 \pi \mathrm{f}_{\mathrm{r}} \mathrm{t}\right)=-1$, the valley of the drain resonance occurs. The drain and source voltages of power MOSFET experience absolute minimum values. It is obvious that the minimum $\mathrm{V}_{\text {out }}$ (i.e. the maximum $\left.\left|\Delta \mathrm{V}_{\text {off }(\mathrm{t})}\right|\right)$ is affected by $\mathrm{C}_{\mathrm{dss}} / \mathrm{C}_{\mathrm{gss}}, \mathrm{N}_{\mathrm{p}} / \mathrm{N}_{\mathrm{s}}$, output voltage $\mathrm{V}_{\mathrm{LED}}$ and the decay factor $\alpha$. These parameters should be carefully considered to guarantee that the divider voltage $V_{Z C D}$ should fall below $V_{\text {ref2 }}$ for effective sensing of ZCD for different output voltage $\mathrm{V}_{\mathrm{LED}}$ under universal input voltage.

Based on the aforesaid analysis, the key parameters and values for ZCD sense circuit are designed and shown in Table $\mathrm{I}$. The divider voltage $\mathrm{V}_{\mathrm{ZCD}}=$ $2 \mathrm{~V}_{\text {out }} / 13, \mathrm{~V}_{\text {ref2 }}=\mathrm{V}_{\text {cc }} / 7$. When $\mathrm{V}_{\mathrm{ZCD}}=\mathrm{V}_{\text {ref2 }}$, a $\mathrm{ZCD}$ signal is sensed. From Eq. (10), it can be derived that

$$
\Delta V_{o n \_s}+\Delta V_{o f f(t)}=\frac{V_{c c}}{14}
$$

Table I. Key values for ZCD sense circuit $(\mathrm{Vcc}=14 \mathrm{~V}$, $\left.\mathrm{R}=50 \mathrm{k} \Omega, \quad \mathrm{T}_{\text {blank }}=2 \mu \mathrm{s}\right)$

\begin{tabular}{|c|c|c|c|c|c|c|c|c|c|}
\hline Symbol & $\mathrm{R}_{1}$ & $\mathrm{R}_{2}$ & $\mathrm{R}_{3}$ & $\mathrm{R}_{4}$ & $\mathrm{R}_{5}$ & $\mathrm{R}_{6}$ & $\mathrm{R}_{\mathrm{g}}$ & $\mathrm{V}_{\text {ref } 2}$ & $\mathrm{~V}_{\text {ZCD }}$ \\
\hline Value & $\begin{array}{c}1800 \mathrm{k} \Omega \\
(36 \mathrm{R})\end{array}$ & $\begin{array}{c}300 \mathrm{k} \Omega \\
(6 \mathrm{R})\end{array}$ & $\begin{array}{c}550 \mathrm{k} \Omega \\
(11 \mathrm{R})\end{array}$ & $\begin{array}{c}100 \mathrm{k} \Omega \\
(2 \mathrm{R})\end{array}$ & $35 \mathrm{k} \Omega$ & $1 \mathrm{k} \Omega$ & $0.5 \mathrm{k} \Omega$ & $\frac{\mathrm{V}_{\mathrm{cc}}}{7}$ & $\frac{2 \mathrm{~V}_{\text {out }}}{13}$ \\
\hline
\end{tabular}


The switching frequency $\mathrm{f}$ is set to be $50 \mathrm{kHz}$, and $\mathrm{C}_{\mathrm{gss}}$ is about $100 \mathrm{pF}$ for the selected power MOSFET. Thus $\mathrm{T}_{\mathrm{on}_{\_} \mathrm{s}}=1 /(2 \mathrm{f})=10 \mu \mathrm{s}, \mathrm{t}=$ $\mathrm{T}_{\text {on_s }}-\mathrm{T}_{\text {blank }}=8 \mu \mathrm{s}$. From Eq. (7), $\Delta \mathrm{V}_{\text {on_s }}=0.66 \mathrm{~V}$. And from Eq. (11), $\left|\Delta \mathrm{V}_{\text {off }(\mathrm{t})}\right|=0.34 \mathrm{~V}$. It means that when the negative change $\Delta \mathrm{V}_{\text {off }(\mathrm{t})}$ for the power MOSFET's source voltage during resonant period is $-0.34 \mathrm{~V}, \mathrm{ZCD}$ signal is sensed.

\section{Experimental results}

The driving IC is implemented in CSMC $0.35 \mu \mathrm{m}$ 5-40 V CMOS process. The key components and parameters of this prototype are as listed in Table II.

Table II. Key components and parameters of the prototype

\begin{tabular}{|c|c|c|c|c|}
\hline Parameters & $\begin{array}{c}\text { AC input } \\
\text { voltage }\end{array}$ & Output power & $\begin{array}{c}\text { Primary-side } \\
\text { inductance }\end{array}$ & $\begin{array}{c}\text { Transformer } \\
\text { core }\end{array}$ \\
\hline Symbol & $\mathrm{V}_{\text {in }}$ & $\mathrm{P}_{\mathrm{o}}$ & $\mathrm{L}_{\mathrm{p}}$ & $1.4 \mathrm{mH}$ \\
\hline Value & $85-265 \mathrm{~V} / 50 \mathrm{~Hz}$ & $3-5 \mathrm{~W}$ & EE13/PC40/TDK \\
\hline Parameters & $\begin{array}{c}\text { Transformer } \\
\text { turns ratio }\end{array}$ & Startup resistor & $\begin{array}{c}\text { Current sense } \\
\text { resistor }\end{array}$ & Bulk capacitor \\
\hline Symbol & $\mathrm{N}_{\mathrm{p}} / \mathrm{N}_{\mathrm{s}}$ & $\mathrm{R}_{\mathrm{st}}$ & $\mathrm{R}_{\mathrm{cs}}$ & $\mathrm{C}_{\mathrm{b}}$ \\
\hline Value & $114: 30$ & $860 \mathrm{k} \Omega$ & $1.43 \Omega$ & $4.7 \mu \mathrm{F} / 450 \mathrm{~V}$ \\
\hline Parameters & $\begin{array}{c}\text { Bypass } \\
\text { capacitor }\end{array}$ & $\begin{array}{c}\text { Output } \\
\text { capacitor }\end{array}$ & $\begin{array}{c}\text { Output rectifier } \\
\text { diode }\end{array}$ & \\
\hline Symbol & $\mathrm{C}_{\mathrm{Vcc}}$ & $\mathrm{C}_{\mathrm{o}}$ & $\mathrm{D}_{\mathrm{o}}$ & $\mathrm{ES} 1 \mathrm{D}$ \\
\hline Value & $1 \mu \mathrm{F} / 50 \mathrm{~V}$ & $10 \mu \mathrm{F} / 50 \mathrm{~V}$ & \multicolumn{2}{|c|}{} \\
\hline
\end{tabular}

The internal reference voltage $\mathrm{V}_{\text {ref1 }}$ is designed to be $0.45 \mathrm{~V}$, and the external current sense resistor is set to be $1.43 \Omega$. The primary peak current is $\mathrm{I}_{\mathrm{pp}}=\mathrm{V}_{\text {refl }} / \mathrm{R}_{\mathrm{cs}} \approx 315 \mathrm{~mA}$, and from Eq. (5), the output current $\mathrm{I}_{\mathrm{LED}}=$ $\mathrm{I}_{\mathrm{pp}} * \mathrm{~N}_{\mathrm{p}} /\left(4 \mathrm{~N}_{\mathrm{s}}\right)=299 \mathrm{~mA}$. Lower $\mathrm{V}_{\text {ref1 }}$ leads to a lower sense resistance $\mathrm{R}_{\mathrm{cs}}$ thus a lower conduction loss for a fixed $\mathrm{I}_{\mathrm{pp}}$. However, if the values of $\mathrm{V}_{\text {ref1 }}$ and $R_{c s}$ are too small, a minor change of $V_{\text {ref1 }}$ or $R_{c s}$ will result in a significant change for the output current.

Driving IC chip and a $650 \mathrm{~V}$ VDMOS chip are packaged together in SOP-8. The wire bond micrograph is shown in Fig. 4 (a). $\$ 25 \mu \mathrm{m} \mathrm{Au}$ bondwires are used. The die sizes of driving IC and VDMOS are $1.05 \mathrm{~mm} \times$ $1.0 \mathrm{~mm}$ and $1.5 \mathrm{~mm} \times 1.5 \mathrm{~mm}$, respectively. The prototype of the proposed converter in Fig. 4 (b) is designed and implemented in a PCB whose dimension is $27 \mathrm{~mm} \times 15 \mathrm{~mm}$.

The experimental results are shown in Fig. 5. In Fig. 5 (a), for a fixed output power, the frequency is kept almost unchanged when input voltage is increased from 85 to $265 \mathrm{~V}$. The frequency develops from 42 to $64 \mathrm{kHz}$ when the output power is increased from about 3 to $5 \mathrm{~W}$ (i.e. output voltage is increased from 9.6 to $16.0 \mathrm{~V}$ ). The results agree with the Eq. (6). In Fig. 5 (b), the current variation is within $\pm 3 \%$ and the efficiency of the prototype exceeds $80 \%$ when the output power ranges from about 3 to $5 \mathrm{~W}$ under universal input voltage. Although the system's auxiliary winding and its relevant rectifier diode, divider resistors are eliminated, the current variation and the efficiency are kept at the same level, as compared with other low power LED drivers ([5] and [6]). 


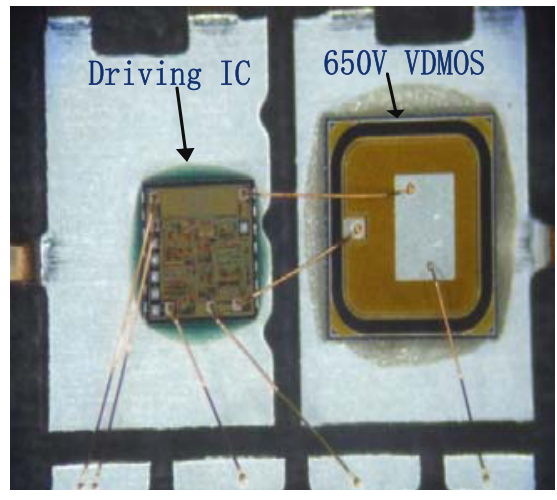

(a)

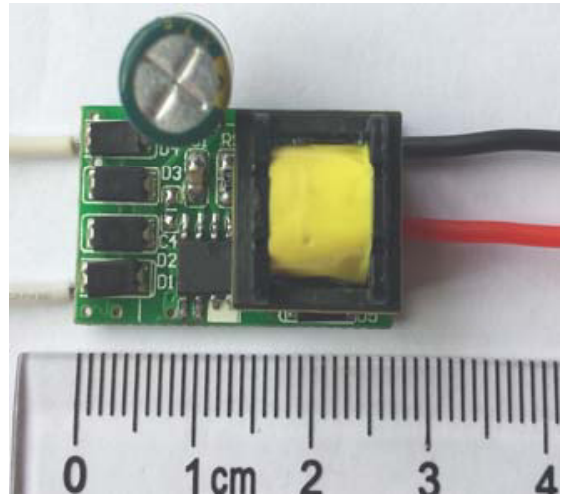

(b)

Fig. 4. (a) Wire bond micrograph of driving IC and VDMOS, (b) Photograph of the driver prototype

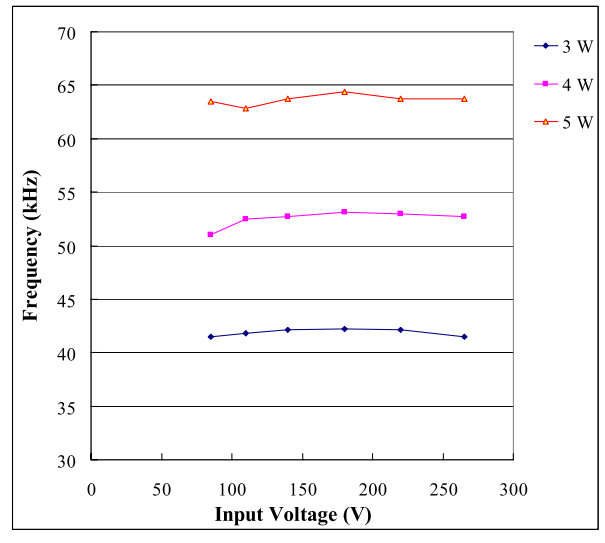

(a)

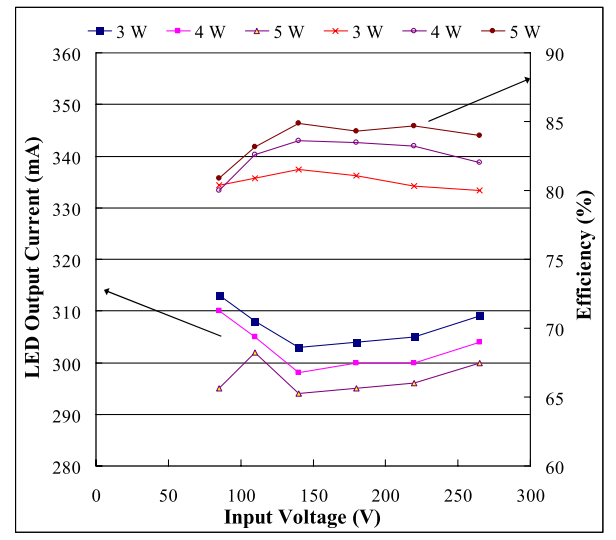

(b)

Fig. 5. (a) Measured frequency, (b) LED output current and efficiency verse input voltage and output power

\section{Conclusions}

We propose a PSR LED driver with auxiliary winding free. The driving IC is realized in $0.35 \mu \mathrm{m} 5-40 \mathrm{~V}$ CMOS process and packaged in SOP-8 together with $650 \mathrm{~V}$ power VDMOS. The ZCD signal is sensed by the negative change of power MOSFET's source voltage due to the resonance of the primary winding with the parasitic capacitor $\mathrm{C}_{\mathrm{dss}}$ of MOSFET. And the auxiliary winding, relevant rectifier diode, divider resistors are eliminated. The LED lighting board is implemented with few external components, and its size is minimized. At the LED-load power ranged from about 3 to $5 \mathrm{~W}$, its current variation is within $\pm 3 \%$, and the efficiency exceeds $80 \%$ under universal voltage ( 85 to $265 \mathrm{~V}$ ). 